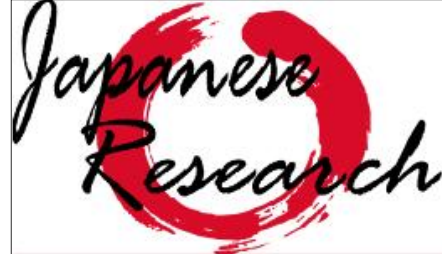

on Linguistics, Literature and Culture
Japanese Research on Linguistics, Literature, and Culture

Vol. 1 No. 2 May 2019, Hal. 144-153

ISSN online: $2655-4836$

http://publikasi.dinus.ac.id/index.php/jrllc/article/view/2677/1599

DOI : 10.33633/ir.v1i2.2677

Published by Universitas Dian Nuswantoro, Semarang

\title{
Pembelajaran Mata Kuliah Japanese Vocabulary 2 dengan Metode Gambar
}

\author{
Diah Soelistyowati \\ Universitas Dian Nuswantoro \\ dyah.soelistyowati@dsn.dinus.ac.id
}

Article History: Submitted date 2019-05-16 ; Accepted date 2019-05-25; Published date 2019-06-01

\begin{abstract}
Japanese Vocabulary 2 courses in Japanese Literature Dian Nuswantoro University are courses that teach Japanese vocabulary which is learned in Kanji letters. This Japanese Vocabulary course is given in semester 3 and semester 4 which is a follow-up course from Japanese Character. However, this study, the author will discuss Japanese Vocabulary 2 learning strategies by using picture slides, drill repetition of words, and Kanji letter vocabulary exercises in Japanese sentences contained in the Goi Nihongo maatome sou N3 textbook and Pea de Oboeru Iroirona Kotoba. The use of this teaching strategy can improve mastery of Japanese Kanji for students to be easy to learn so that learning targets set by Japanese Vocabulary 2 teaching goals can be achieved.
\end{abstract}

Keywords: Japanese Vocabulary, Japanese kanji learning strategy

\begin{abstract}
Abstrak
Mata kuliah Japanese Vocabulary 2 di Program Studi Sastra Jepang Universitas Dian Nuswantoro adalah mata kuliah yang mengajarkan kosa kata bahasa Jepang yang dipelajari dalam huruf-huruf kanji. Mata kuliah Japanese Vocabulary ini diberikan pada semester 3 dan semester 4 yang merupakan mata kuliah lanjutan dari Japanese Character. Namun pada penelitian ini penulis membahas strategi pembelajaran Japanese Vocabulary 2 dengan menggunakan slide gambar, drill pengulangan kata, dan latihan-latihan kosa kata huruf Kanji dalam kalimat bahasa Jepang yang terdapat dalam buku ajar Goi Nihongo maatome sou N3 dan Pea de Oboeru Iroirona Kotoba. Penggunaan strategi pengajaran ini dapat meningkatkan penguasaan huruf kanji bahasa Jepang bagi mahasiswa menjadi mudah dipelajari, sehingga target pembelajaran yang ditetapkan sesuai dengan tujuan pengajaran Japanese Vocabulary 2 dapat tercapai.
\end{abstract}

Kata Kunci: Pembelajaran,kosakata bahasa Jepang,Japanese Vocabulary 


\section{Pendahuluan}

Bahasa merupakan alat komunikasi dan sekaligus alat untuk belajar. Melalui penggunaan bahasa mahasiswa belajar dari berbagai sumber antara lain dari buku, media massa, melalui interaksi dengan teman sebaya atau interaksi dengan lingkungan. Kemampuan berbahasa yang baik memungkinkan penyampaian dan penerimaan pesan atau pengetahuan yang baik, pengolahan dan penyimpanan pengetahuan yang baik.

Kindaichi yang merupakan salah seorang pakar linguistik bahasa Jepang mengklasifikasikan karakteristik-karakteristik bahasa Jepang ke dalam 5 kelompok besar yaitu hatsuon, moji, goi, bunpo dan hyogen (yang secara berurutan dalam bahasa Indonesia adalah ucapan, huruf, kosa kata, tata bahasa dan ekspresi). Unsur-unsur bahasa Jepang meliputi huruf kanji, cara baca kanji, hitsujun (cara penulisan kanji), bushu (bagian kanji yang menentukan arti), rikusho (pembentukan dan pemakaian kanji), hiragana dan katakana serta fungsinya masing-masing. Huruf kanji berasal dari Cina. Pada mulanya orang Cina zaman dahulu menggambar benda-benda yang ada di sekitar mereka. Gambar-gambar tersebut kemudian dibuat sesederhana mungkin dan digambar dalam bentuk kotak-kotak untuk memudahkan mereka dalam menuliskannya. Kanji adalah salah satu jenis huruf yang mempunyai ciri tersendiri terutama dalam cara baca dan cara penulisannya. Meskipun kanji sering disebut sebagai huruf yang sangat rumit dan sukar untuk dipelajari, namun kanji merupakan huruf yang sangat penting dalam bahasa Jepang karena setiap huruf menyatakan arti. Bahasa Jepang banyak memiliki kosakata yang memiliki ucapan yang sama, tetapi dengan adanya kanji maka kesalahan pengertian dapat dihindari.

Dalam pelaksanaan proses pembelajaran bahasa Jepang, terutama dalam hal pengenalan penulisan huruf Kana (Hiragana dan Katakana) dan huruf Kanji sering terdapat masalah yaitu mahasiswa mengalami kesulitan dalam mencapai suatu kompetensi dasar. Hal ini dikarenakan penguasaan kosakata bahasa Jepang yang masih belum dikuasai, sehingga tidak dapat mencapai kompetensi seperti yang tertera dalam kurikulum. Mahasiswa sering kesulitan memahami arti sebuah kata karena pemahaman kosakata mereka relatif kurang memadai sehingga proses pencapaian suatu kompetensi dasar akan berjalan lebih lama. 
Pada umumnya mahasiswa program studi Sastra Jepang menghapal huruf kanji dalam jumlah yang sangat banyak merupakan satu hal yang sulit, akhirnya muncul kesan dari mereka bahwa kanji tersebut "sukar diingat tapi mudah dilupakan", "menyeramkan" dan lain lain. Mahasiswa sering menganggap bahwa mata kuliah yang paling sulit adalah pembelajaran huruf Kanji. Hal tersebut semakin mempersulit dan menjadi penghambat bagi kelancaran pembelajaran bahasa Jepang. Hal ini dikarenakan secara keseluruhan tanpa keterampilan membaca dan menulis huruf kanji menjadi hambatan bagi mahasiswa tersebut mengikuti mata kuliah lainnya, seperti mata kuliah menyimak, terjemahan dan lainlain.

Apabila mahasiswa mengalami kesulitan dalam memahami arti sebuah kata selama proses pembelajaran maka dengan terpaksa akhirnya pengajar memberikan jalan pintas dengan cara: (1) Menentukan konteks situasi sebagai tema kosa kata; (2) Mengajak mahasiswa untuk berpikir dan menentukan bersama-sama kosa kata yang digunakan dalam konteks situasi tersebut; (3) Menyuruh mahasiswa mencari arti kata tersebut dan mempelajarinya dalam kamus ; (4) Saat mahasiswa mengalami kesulitan dalam mencari dan mendefinisikan arti kosa kata, pengajar akan menjelaskannya.

Dengan demikian permasalahannya adalah bagaimanakah proses pembelajaran Japanese Vocabulary dapat memudahkan mahasiswa dalam menguasai huruf kanji di semester 3 dan 4. Berdasarkan kendala-kendala di atas maka dalam penelitian ini menggunakan teknik dan strategi agar pemahaman kosa kata bahasa Jepang mahasiswamahasiswa di jurusan Sastra Jepang Universitas Dian Nuswantoro agar dapat meningkat, karena itu mahasiswa tidak selalu bergantung pada kamus atau menunggu jawaban dari pengajar dalam memahami arti kosa kata bahasa Jepang, sehingga hal ini diharapkan akan memudahkan pencapaian suatu kompetensi berbahasa sekaligus meningkatkan pemahaman mahasiswa terhadap huruf-huruf Kanji yang terdapat pada kosa kata bahasa Jepang.

Selama memberikan mata kuliah Japanese Vocabulary sebagai mata kuliah wajib, seiring dengan perkuliahan selama itu, banyak metode yang diterapkan untuk mempermudah pembelajaran kanji yang dianggap sebagai mata kuliah yang paling sulit bagi mahasiswa, terutama metode yang mempermudah untuk mengingat huruf kanji, antara lain 
dengan metode mengingat cerita asal usul kanji tersebut, melalui pemahaman komponen kanji (bushu), dari huruf bergambar (emoji) dan lain-lain.

\subsection{Kajian Teoretis}

Dalam membicarakan pengajaran dan pembelajaran bahasa, lingkungan merupakan sesuatu yang sangat penting dalam kaitan dengan keberhasilan pembelajaran bahasa itu. Menurut Abdul Hamied dalam Suherman, A (2001) terdapat dua faktor lingkungan, yaitu makro dan mikro. Faktor lingkungan makro meliputi (1) kealamiahan bahasa yang didengar; (2) peranan si pembelajar dalam komunikasi; (3) ketersediaan rujukan konkret untuk menjelaskan makna; dan (4) siapa model bahasa sasaran. Sedangkan faktor lingkungan mikro mencakup (1) kemenonjolan (salience), yaitu mudahnya suatu struktur untuk dilihat atau didengar; (2) umpan balik, yaitu tanggapan pendengar atau pembaca terhadap tuturan atau tulisan si pembelajar; dan (3) frekuensi, yaitu seringnya si pembelajar mendengar atau melihat struktur tertentu. Selanjutnya berkenaan dengan faktor lingkungan mikro, yang pertama adalah kemenonjolan. Kemenonjolan ini merujuk pada kemudahan suatu struktur dilihat atau didengar. la adalah ciri tertentu yang tampaknya membuat suatu butir secara visual atau auditor lebih menonjol dari pada yang lain. Faktor lingkungan mikro yang kedua adalah umpan balik. Salah satu jenis umpan balik adalah pembetulan, yang lainnya adalah persetujuan atau umpan balik positif. Faktor lingkungan mikro yang ketiga adalah frekuensi yang diasumsikan sebagai faktor berpengaruh terhadap pemerolehan bahasa. Makin banyak si pembelajar mendengar suatu struktur, makin cepat proses pemerolehan struktur itu.

Pembelajaran kosa kata oleh karenanya hendaknya dikaitkan dengan fungsi bahasa sebagai alat komunikasi. Kosa kata hendaknya tidak dipandang sebagai daftar panjang katakata yang harus didefinisikan dan dihafalkan. Sebaliknya, kosa kata hendaknya dilihat peran pentingnya dalam penggunaan bahasa secara kontekstual dan bermakna. Brown (2001, 377378) memberikan rambu-rambu pengajaran kosa kata yang komunikatif sebagai berikut:

1. Ada waktu khusus untuk pembelajaran kosa kata

2. Siswa belajar kosa kata dalam konteks

3. Penggunaan kamus monolingual ditingkatkan

4. Siswa didorong untuk mengembangkan strategi untuk menebak makna kata

5. Pembelajaran kosa kata yang tidak terencana dapat terjadi 
Strategi yang digunakan untuk membaca teks bacaan bahasa Jepang dalam buku 日 本語教授法シリーズ第 7 「読むことを教える」Nihongo Kyoujouhou Shiriizu Dai 7 Kyoujuhou Shiriizu Dai $7\lceil$ Yomu koto wo Oshieru」menjelaskan langkah-langkahnya sebagai berikut :

1. Memastikan arti kata-kata baru

2. Mencari informasi penting dengan cepat

3. Merangkum ringkasan keseluruhan dan membaca secara sepintas lalu

4. Melanjutkan membaca sambil menduga maknanya

5. Membaca sambil memikirkan hubungan kalimat dengan kalimat serta memperhatikan kata tunjuk dan kata sambung

6. Menemukan kalimat dan kata-kata penting dengan membaca cepat pada kalimat seterusnya

7. Menyusun isi dengan detail pada daftar atau peta.

Berdasarkan uraian tersebut di atas penulis ingin menguraikan tentang pengajaran mata kuliah Japanese Vocabulary tersebut dengan menggunakan strategi dan metode pembelajaran kosa kata bahasa Jepang.

\subsection{Metode Penelitian}

Metode penelitian yang digunakan dalam penelitian ini adalah metode penelitian deskriptif kualitatif yaitu menggambarkan strategi pengajaran Japanese Vocabulary pada semester 3 dan 4 pada Program Studi Sastra Jepang Universitas Dian Nuswantoro Semarang. Subyek penelitian ini adalah mahasiswa semester 3 dan 4 yang mengambil matakuliah Japanese Vocabulary. Strategi pengajaran menggunakan metode gambar untuk mengingat huruf kanji yang diambil dari buku Goi Nihongo So-Matome N3 karya Noriko Matsumoto \& Hitoko Sasaki dan buku Pea de Oboeru Iroirona Kotoba karya Akimoto Miharu.

\section{Hasil dan Pembahasan}

Berikut adalah materi pengajaran di jurusan Sastra Jepang di Universitas Dian Nuswantoro yang diambil dari silabus matakuliah Japanese Vocabulary 1

Mata kuliah ini membahas cara penggunaan huruf kanji dalam pelajaran yang terdapat dalam buku Pea de Oboeru Iroirona Kotoba dan penguasaan kosakata untuk mahasiswa agar dapat menguasai level N3. Setelah menempuh mata kuliah ini mahasiswa 
diharapkan dapat menerapkan penggunaan huruf kanji yang terdapat pada kalimat bahasa Jepang level N3 agar dapat mengingat dengan mudah dan lancar.

Materi dilanjutkan pada mata kuliah Japanese Vocabulary 2 dengan menggunakan buku ajar Nihongo So-Matome N3 Goi pada semester 4. Adapun materi yang digunakan dari buku tersebut adalah sebagai berikut.

1. Kaji o shimashou 'ayo mengerjakan pekerjaan rumah' berisi peralatan di dapur di ruang tamu, cara memasak masakan, memelihara binatang piaraan, mencuci, dan membersihkan rumah.

2. Gaishutsu shimashou 'mari pergi keluar' berisi membuat rencana, cara naik kereta api, naik mobil, dan urusan keperluan di Bank.

3. Kyuujitsu o tanoshimashou 'bersenang-senang pada hari libur' berisi mengajak kencan, model baju, berbelanja macam-macam baju, pergi makan keluar, mengajak minum sake, dan cara-cara pembayaran.

4. Benkyou ya shigoto o shimashou 'mari belajar dan bekerja' membahas pergi ke sekolah, matakuliah jurusan dan ujian, jenis-jenis pekerjaan, cara pemakaian laptop, dan cara menulis e-mail

5. Iro iro hyougen shimashou 'macam-macam ungkapan' berisi istilah hubungan keluarga, mengucapkan salam, sifat orang yang disukai, kondisi keadaan badan, menjelaskan ungkapan ekspersi seseorang.

6. Matomete oboemashouv'menghapalkan keseluruhan' membahas bagaimana mengungkapkan semangat, ungkapan perasaan, dan ungkapan verba.

Materi yang membahas kosa kata tersebut disampaikan dalam 1 (satu) semester $14 \mathrm{X}$ tatap muka, dengan langkah-langkah kegiatan pembelajaran Japanese Vocabulary 2 sebagai berikut.

Mata kuliah ini pertama-tama membahas pemahaman kosakata dalam bentuk latihan atarashii goi 'kosa kata baru' yang terdapat dalam sebuah wacana. Seperti contoh materi berikut : 


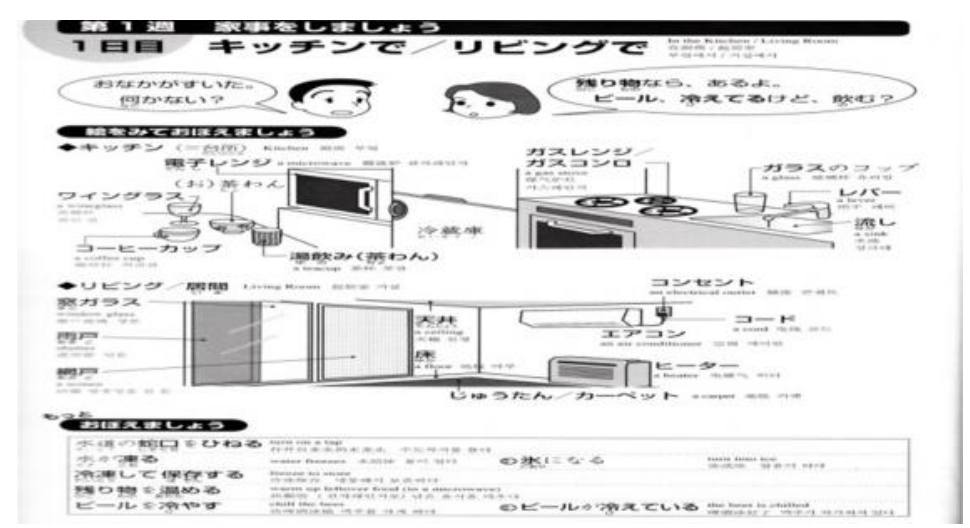

Gambar 1. Teks bacaan ( Sumber buku Goi Nihongo soumatome N3)

Kemudian cara-cara yang dilakukan pengajar pada step ini adalah menebak gambar yang terdapat pada powerpoint lalu dengan media gambar tersebut mahasiswa mengenal kosa kata baru berupa huruf kanji tersebut. Contoh materi seperti media gambar di bawah ini. Kuruma ni norimashou 'Ayo naik mobil'. Sebelum membahas arti kata pada kosa kata tersebut, mahasiswa diajak berpikir tentang gambar yang ditanyakan. Penggunaan gambar untuk mengetahui kosa kata baru yang dimaksud.

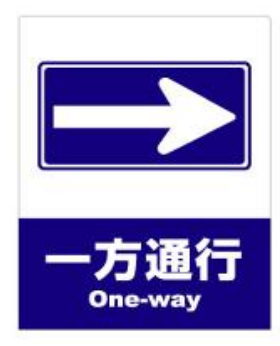

Gambar2.ippou tsuukou 'jalan searah'

Gambar 3. tsuukoudoe : 'jalan ditutup'

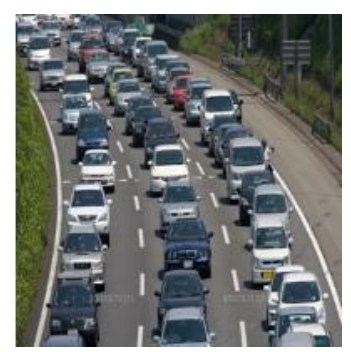

Gambar 4. Juutai 'jalan macet'

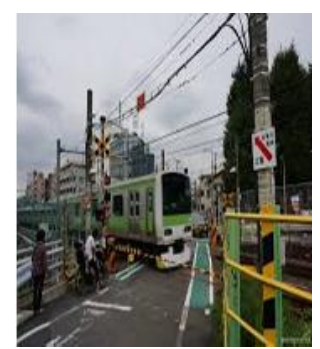

Gambar 5. fumikiri 'palang pintu rel'
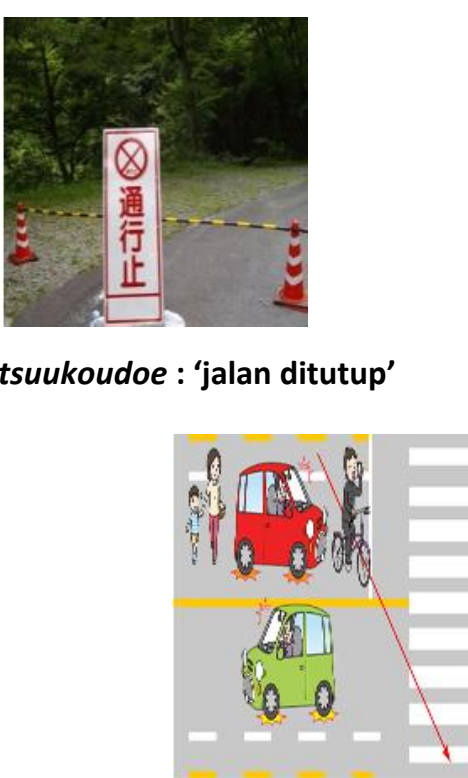

Gambar 6. nanamenioudan suru 'menyeberang serong ke samping'

1) Membahas pemahaman kosa kata berbentuk latihan membaca dalam huruf Kanji dan mencari arti kata dari kosa kata tersebut. Tidak hanya sebatas pengenalan dan 
pemahaman kosa kata saja, namun juga diurutkan sesuai gambar yang sudah dibahas dan menyebutkannya kembali.

2) Menuliskan kembali huruf kanji yang terdapat dalam kosa kata tersebut. Cara-cara yang dilakukan pengajar pada step ini adalah sebagai proses drill mengulang kosa kata, mahasiswa diminta menyebutkan kembali kosa kata yang sudah diajarkan sesuai gambar yang tersedia. Kemudian dengan menggunakan metode gambar, mahasiswa diajak menghapal dan mengingat kosa kata dan penulisan kanjinya. Selain itu sebagai variasi dalam mengajarkan mahasiswa diberikan game yang berhubugnan dengan materi kosa kata yang disampaikan.

3) Membahas kosa kata tersebut yang terdapat dalam kalimat bacaan di tiap-tiap materi.

4) Mengulang kosa kata tersebut dengan menggunakan metode drill. Metode latihan siap (drill) adalah cara mengajar melatih ketangkasan dan keterampilan siswa. biasanya digunakan untuk pelajaran yang bersifat motorik, latihan kecakapan mental, berpikir, membaca peta, penggunaan simbol dan lain-lain, digunakan untuk melatih ulang pelajaran yang diberikan dan memperkuat daya ingat dalam menghapalkan.

5) Setelah itu dilakukan review atau pengulangan semua materi kosa kata yang telah disampaikan pada pertemuan tersebut.

6) Akhir pertemuan perkuliahan diberikan latihan 練習(れんしゅう)untuk mengetahui sejauh mana pemahaman mahasiswa pada materi pertemuan tersebut. Latihan tersebut berupa kosa kata yang digunakan dalam kalimat bahasa Jepang seperti contoh berikut ini. 


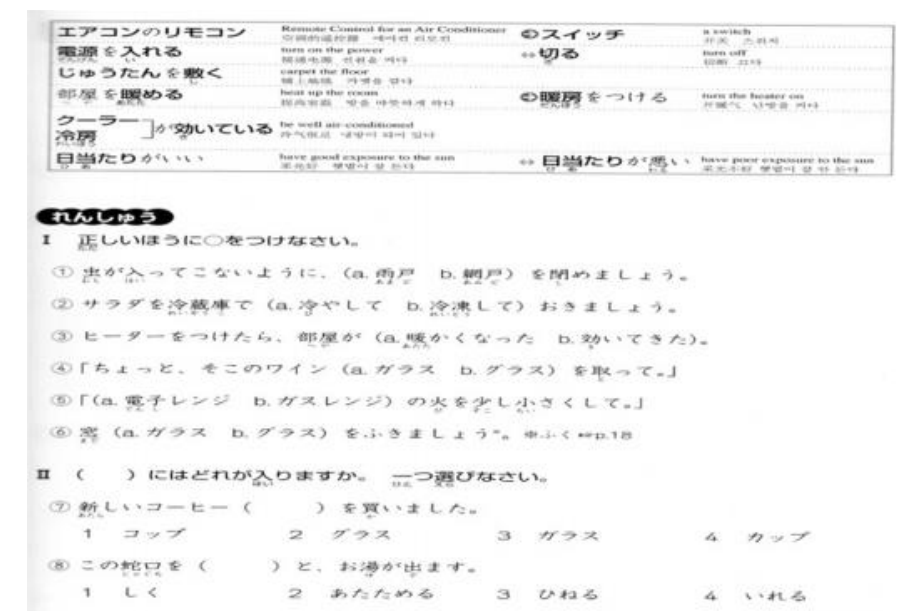

Gambar 7. Latihan soal (Sumber buku Goi Nihongo soumatome N3)

\section{Simpulan}

Pembelajaran mata kuliah Japanese Vocabulary 2 di Jurusan Sastra Jepang Universitas Dian Nuswantoro dapat membantu mahasiswa dalam mengingat kosa kata baru berupa huruf-huruf kanji yang terdapat dalam wacana bacaan buku ajar yang digunakan. Penyampaian materi Japanese Vocabulary 2 menggunakan strategi metode gambar, drill pengulangan kata, dan latihan-latihan kosa kata huruf Kanji yang dipakai dalam kalimat bahasa Jepang. Adanya langkah-langkah kegiatan strategi pembelajaran Japanese Vocabulary 2 dengan menggunakan metode gambar dapat meningkatkan kemampuan mahasiswa dalam menguasai materi kosa kata tersebut. Permasalahan yang dihadapi mahasiswa dengan menggunakan metode tersebut dapat dikuasai huruf kanji tersebut dengan mudah, sehingga target pembelajaran yang ditetapkan sesuai dengan tujuan pengajaran Japanese Vocabulary 2 dapat tercapai.

\section{Daftar Pustaka}

Brown, H. D. (2001). Teaching by Principles. Addison Wesley Longman, Inc, White Plain, NY. Isao, Matsumoto. (2006). 日本語教授法シリーズ第 7 「読むことを教える」Nihongo Kyoujouhou Shiriizu Dai 7 Kyoujuhou Shiriizu Dai 7 「Yomu koto wo Oshieru」, The Japan Foundation, Japan.

Matsumoto, Noriko \& Hitoko Sasaki. (2010). 語彙・日本語総まとめ N3 (Goi Nihongo soumatome N3), Asuku Shuppan, Japan.

Miharu, Akimoto etc. (2000). ペアで覚えるいろいろなことば ( Pea de Oboeru Iroirona Kotoba ), Mushashinoshouin. Tokyo. 
Saifudin, A. (2018). Penggunaan Manga Humor dalam Pembelajaran Bahasa dan Penelitian Bahasa Jepang. JAPANEDU: Jurnal Pendidikan dan Pengajaran Bahasa Jepang 2 (2), 99-113.

Suherman, A. (2001). Bahan Pembelajaran / Pembelajaran Bahasa Asing. http://file.upi.edu/Direktori/FPBS/JUR. PEND. BAHASA ARAB/195105081980031-

A. SUHERMAN/BAHAN PEMBELAJARAN/PEMBELAJARAN BAHASA ASING.pdf diakses tanggal 5 Juni 2019.

Syaodih Sukmadinata, Nana \& Erliana Syaodih. (2012), Kurikulum \& Pembelajaran Kompetensi, Refika Aditama, Bandung.

Takebe, Yoshiaki. (1982). Kanji no Yoohoo, Kakugawa Shoten, Tokyo.

Yoshio dkk. (1990), Nihongo No Kyouiku Handobukku, Taishuukan Shoten, Tokyo. 